\title{
Educação e inclusão social das crianças e dos adolescentes
}

\author{
Amélia Maria Noronha P. de Queiroz*
}

\section{Resumo}

Este artigo trata da inclusão social de crianças e adolescentes, tendo a educação como principal agente de mudança, visando a atingir nivel de desenvolvimento humano desejável. Para conhecer a situação atual, foi feita breve análise da legislação referente à criança e ao adolescente no Brasil, assim como dos indicadores de saúde e educação baseados em dados do Ministério da Educação, da Saúde, da Pesquisa Nacional por Amostra de Domicílios (PNAD), do Instituto Brasileiro de Geografia e Estatística (IBGE) e da realidade da relação educação e trabalho. É apresentada proposta de criação de Polos, focando principalmente escolas, postos de saúde e de assistência social já existentes, que seriam definidos num processo democrático sociopolítico, envolvendo Governo e Sociedade. Os protagonistas das ações seriam profissionais de reconhecida competência para desenvolver a proposta, incluindo as funções de monitoramento, acompanhamento e avaliação necessários para maior eficiência e eficácia de suas ações e a quem seriam concedidas condições de trabalho fisicas e financeiras compatíveis com sua função, assim como possibilidade de ascensão profissional.

Palavras-chave: Educação e inclusão. Educação e leis federais. Educação e saúde. Trabalho e educação infanto-juvenil. Escolas-polo.

\section{Education and the Social Inclusion of Children and Teenagers Abstract}

This article deals with the proposal for social inclusion of children and teenagers, having education as the main changing agent, aiming to give them a desirable level of human development. In order to understand the current situation, we present an abbreviated analysis of the legislation related to Brazilian children and teenagers, as well as indicators of health and education, based on data from the

Doutora em Educação, Universidade Federal do Rio de Janeiro (UFRJ); professora estadual; ex-professsora da Pontifícia Universidade Católica do Rio de Janeiro (PUC-Rio). E-mail: amnpq@globo.com 
Ministry of Health, Education, PNAD, IBGE, and the reality of the relationship education and work. We propose the creation of Poles, focusing mostly schools, health posts and social assistance posts already existent, that should be defined in a democratic socio-political process, involving Government and Society. The protagonists of the actions should be professionals of well-known competence to develop the proposal, including the functions of monitoring, following-up and evaluating needed for the best efficiency and effectiveness of their actions and to whom physical and financial working conditions, compatible with their functions, should be granted as well as the possibility of professional promotion.

Keywords: Education and social inclusion. Education and federal laws. Education and health. work and basic education. Pole schools.

\section{Educación e inclusión social de los niños y de los adolescentes}

\section{Resumen}

Este artículo trata sobre la inclusión social de niños y adolescentes, y tiene a la educación como principal agente de cambio, y por objeto alcanzar nivel de desarrollo humano deseable. Para conocer la situación actual se hizo un breve análisis de la legislación referente al niño y al adolescente en Brasil, y de los indicadores de salud y educación basados en datos del Ministerio de Educación, de Salud, del Pesquisa Nacional por Muestras de Domicilio (PNAD), del Instituto Brasileño de Geografía y Estadistica (IBGE) y de la realidad de la relación educación y trabajo. Se presenta la propuesta de creación de Polos, focalizando principalmente escuelas, puestos de salud y de asistencia social ya existentes, que serían definidos en un proceso democrático sociopolítico, involucrando Gobierno y Sociedad. Los protagonistas de las acciones serían profesionales de reconocida competencia para desarrollar la propuesta, incluyendo las funciones de monitoreamiento, acompañamiento y evaluación necesarios para una mayor eficiencia y eficacia de sus acciones y a quien serían concedidas condiciones laborales físicas y financieras compatibles con su función, así como posibilidad de ascenso profesional.

Palabras clave: Educación e inclusión. Educación y leyes federales. Educación y salud. Trabajo y educación infanto-juvenil. Escuelas-Polo.

0 problema das populações que vivem à margem da sociedade tem sido objeto de preocupação de governos e da sociedade. A situação dramática das crianças e dos jovens dessas populações clama por soluções urgentes e eficazes. Há mais de 20 anos Tancredo Neves, ao discursar, enquanto Governador de Minas Gerais, em despacho de dezembro de 1983, preconizando o Estatuto da Criança e do Adolescente (ECA), dizia: "A criança é a nossa mais rica matéria-prima. Abandoná-la à sua própria sorte ou desassisti-la em suas necessidades de proteção e amparo é crime de lesa-pátria" (NEVES, 1983 apud VASCONCELOS JÚNIOR, [200?], p. 7). Entre tenta- 
tivas de solução para esse problema, talvez a mais contundente e expressiva seja o ECA (BRASIL, 1990), que tem como princípio básico, que a criança é sujeito de direitos e tem condição peculiar de pessoa em desenvolvimento. Entretanto, vige há mais de 20 anos e até hoje está longe de corresponder às expectativas.

Aqui é apresentada uma proposta de solução, tomando a escola como lócus de planejamento, monitoramento e avaliação de programa de desenvolvimento humano, segundo o conceito do Programa de Desenvolvimento das Nações Unidas (PNUD) (BRASIL, 1990), observando determinações da Constituição Brasileira (BRASIL, 1988) e do ECA (BRASIL, 1990), e considerando resultados de análise da situação da criança e do adolescente no Brasil.

Breve análise da legislação referente à criança e ao adolescente no Brasil: Estatuto da Criança e do Adolescente (BRASIL, 1990), Constituição (BRASIL, 1988) e Relatório do Desenvolvimento Humano (UNITED NATIONS DEVELOPMENT PROGRAMME, 1990)

A Constituição (BRASIL, 1988) em seu artigo 226, parágrafo 8, diz: "0 Estado assegurará a Assistência à família na pessoa de cada um dos que a integram, criando mecanismos para coibir a violência no âmbito de suas relações e, no artigo 227: "É dever da família, da sociedade e do Estado assegurar à criança e ao adolescente, com absoluta prioridade, o direito à vida, à saúde, à educação, ao lazer, à profissionalização, à cultura, à dignidade, à convivência familiar, à convivência comunitária, além de colocá-los a salvo de toda forma de negligência, discriminação, exploração, violência, crueldade e opressão" (BRASIL, 1988).

0 princípio deste artigo se repete no Artigo 4 do ECA, que substitui a palavra "Estado" por "Poder Público" e a expressão "direito a" por "efetivação dos direitos a", acrescenta esporte entre os direitos e o artigo 5, quase repete o restante do caput do artigo 227: "Nenhuma criança ou adolescente será objeto de negligência, discriminação, exploração, violência, crueldade e opressão, punido na forma da lei qualquer atentado ou ação ou omissão aos seus direitos fundamentais".

0 então senador Ronan Tito de Almeida (1990, p. 19), por ocasião da entrega do prêmio Criança e Paz do Congresso Nacional Brasileiro pelo Fundo das Nações Unidas para a Infância (Unicef), na apresentação da justificativa do ECA dizia:

as crianças e os jovens das famílias de baixa renda nas periferias urbanas e nas áreas rurais pauperizadas são verdadeiras ilhas cercadas de omissão por todos os lados. Sua condição de subcidadãos se espelha no subsalário, no desemprego ou no subemprego, na submoradia, na subnutrição, configurando, assim, total desatendimento dos seus direitos individuais à vida, à liberdade, ao respeito, à dignidade, bem como de seus direitos coletivos-econômicos, sociais e culturais-, cuja garantia, com absoluta prioridade, é agora, por mandato constitucional, 'dever da família, da sociedade e do Estado'. 
Infelizmente, passados mais de 20 anos, a situação ainda permanece muito longe de se tornar realidade, como se pode concluir, ao analisar o quadro que se segue comparando as determinações legais e a realidade brasileira.

\section{Quadro 1 - Constituição de 1988: Artigo 227.}

\begin{tabular}{|c|c|}
\hline \multicolumn{2}{|c|}{ Constituição, Art. 227: "é dever da família, da sociedade, do Estado [...] assegurar o direito à } \\
\hline$\sqrt{1}$ & REALIDADE \\
\hline Vida & $\begin{array}{l}\text { Segundo o Ministério da Saúde (MS), o índice de mortalidade infantil no Brasil } \\
\text { passou de } 28,4 \text { em cada } 1000 \text { (em 1999) para 20,4 em } 2006 \text { (SIM/SVS/MS), e no } \\
\text { município do Rio de Janeiro, melhorou } 27 \text { posições na graduação da taxa de } \\
\text { mortalidade para crianças de menos de cinco anos de idade, passando de } 57 \\
\text { mortes de menores de cinco anos por } 1000 \text { nascidos, em } 1990 \text {, para } 33 \text { em } 2008 \text {. Os } \\
\text { altos índices de mortes por doenças também diminuíram nesse período. } 0 \text { índice de } \\
\text { mortes por violência, sobretudo homicídios é muito alto; em 2008, era de } 1,0 \text { por } \\
100 \text { mil na faixa de } 0 \text { a quatro anos, de } 0,7 \text { na faixa de cinco a nove anos, } 3,7 \text { na } \\
\text { faixa de } 10 \text { a } 14 \text { anos, } 44,5 \text { de } 15 \text { a } 19 \text { anos e } 58,8 \text { na de } 20 \text { a } 29 \text { anos (BRASIL, 2009). }\end{array}$ \\
\hline Saúde & $\begin{array}{l}\text { A morte da maioria das crianças de até um ano de idade, excluindo problemas } \\
\text { congênitos e do sistema nervoso, se deve, sobretudo, a problemas respiratórios e intes- } \\
\text { tinais, segundo dados do DATASUS (BRASIL, 2009), na maioria das vezes evitáveis, com } \\
\text { a educação para a saúde dos pais ou responsáveis e melhor assistência médica. }\end{array}$ \\
\hline Alimentação & $\begin{array}{l}0 \text { índice de desnutrição de crianças até um ano de idade diminuiu de } 1989 \\
\text { para 2006, passando de } 7,1 \text { a } 1,8 \text { por mil nascidos vivos, mas ainda precisa } \\
\text { baixar (BRASIL, 2009). }\end{array}$ \\
\hline Educação & $\begin{array}{l}0 \text { analfabetismo total (pessoas que não sabem ler nem escrever) na faixa de } \\
\text { sete a } 14 \text { anos compreende 1,8 milhões de pessoas e de } 15 \text { anos e mais é de 9,7 } \\
\% \text { (IBGE, 2010), que correspondem a 14,1 milhões de pessoas em } 2008 \text { (IBGE, } \\
\text { 2010), e 20,3\%, ou seja, um em cada cinco brasileiros, aproximadamente, é } \\
\text { analfabeto funcional*, portanto, incapaz de bem ler e interpretar textos. }\end{array}$ \\
\hline Cultura & $\begin{array}{l}\text { A maioria dos municípios não tem espaço cultural apropriado e a expressão } \\
\text { artística raramente é incentivada. A maioria da população não tem acesso a } \\
\text { espaços públicos de lazer ou espaços culturais tais como cinemas, teatros, } \\
\text { praças públicas e museus. }\end{array}$ \\
\hline Profissionalização & $\begin{array}{l}\text { Lamentavelmente, a PNAD revelou haver } 2,0 \text { milhões de crianças e jovens de } \\
\text { cinco a } 15 \text { anos no mercado de trabalho, sendo que } 122.679 \text { delas, ou seja, } \\
0,8 \% \text { têm de cinco a nove anos de idade. (IBGE, 2010). Geralmente, trata-se de } \\
\text { trabalho de baixa remuneração, quase escravo. }\end{array}$ \\
\hline Dignidade $[\ldots[$ & $\begin{array}{l}\text { Constatam-se, com frequência, casos de violência doméstica, praticados por } \\
\text { problemas de alcoolismo dos pais ou responsáveis, por excesso de agressividade } \\
\text { geralmente causada por falta de recursos para atender às necessidades básicas } \\
\text { da família. Segundo a PNAD } 2009 \text { (IBGE, 2009), o percentual de escolares } \\
\text { frenquentando o 9.ano do Ensino Fundamental expostos à violência da parte } \\
\text { da família chega a 9,5\% (IBGE, 2010). }\end{array}$ \\
\hline
\end{tabular}

Fonte: Brasil (1988).

Nota: * pessoa de 15 anos ou mais "sem domínio de habilidades em leitura, escrita, cálculo e ciências em correspondência com uma escolaridade mínima das quatro primeiras séries completas" (IBGE, 2010). 
No Relatório Human Development Report (UNITED NATIONS DEVELOPMENT PROGRAMME, 1990, tradução nossa), há uma citação de Aristóteles, que já via "a diferença entre uma política boa ou má como o sucesso ou o fracasso na habilidade de levar as pessoas a uma vida florescente". Foi também colocada neste Relatório, como um ponto crucial na definição de políticas sociais básicas, a perspectiva de que o desenvolvimento de uma nação não se mede apenas por renda per capita, menos ainda por PNB ou PIB; o desenvolvimento humano passou a ser entendido como o processo de oferecer às pessoas oportunidades na vida. Resumem-se em três as principais destas oportunidades: 1) uma vida longa e saudável, 2) aquisição de conhecimento, através de estudo e escolarização e 3) ter recursos para satisfazer as necessidades básicas, de acordo com um padrão de vida digno.

Os Relatórios de Desenvolvimento Humano, elaborados inicialmente pelo Programa das Nações Unidas para o Desenvolvimento (PNUD), em termos de indicadores brasileiros, associaram-se ao Instituto de Pesquisa Econômica Aplicada (IPEA), à Fundação João Pinheiro e ao Instituto Brasileiro de Geografia e Estatística (IBGE), reconsiderando os parâmetros para a definição de índice de desenvolvimento humano. Levou em conta três parâmetros fundamentais: 1) longevidade, compreendendo a esperança de vida ao nascer; 2) educação, compreendendo a taxa de analfabetismo e o número médio de anos de estudo e 3) a renda familiar PIB per capita (em dólar PPC - paridade de poder de compra). Esse relatório é publicado anualmente, tendo como pressuposto que, para aferir o avanço da população, é preciso considerar a condição econômica e também outras características sociais, culturais e políticas que também influenciam a qualidade de vida

0 estudo salienta outras oportunidades importantes para o desenvolvimento humano: liberdade econômica, social e política, garantia dos direitos humanos; ser criativo e gozar de respeito pessoal. Ele entende, ainda, que o desenvolvimento humano apresenta duas vertentes: de um lado, a formação de capacidades humanas (melhoria da saúde, conhecimento), de outro lado, o uso que as pessoas fazem das capacidades adquiridas, seja com propósitos produtivos, para lazer ou para participarem ativamente de atividades culturais, sociais e políticas. "Desenvolvimento, portanto, deve ser mais do que apenas a expansão de renda e riqueza. Seu foco deve ser a pessoa humana" (BRASIL, 1990b).

Segundo o citado relatório, o Brasil, que ocupava o 69 lugar em 1990, passou a ocupar o $75^{\circ}$ lugar (com índice 0,813 ) em 2007. 0 índice de analfabetismo (de pessoas de 15 anos e mais), que era de 15, 1\% em 1999 (PNUD), passou para 9,7\%, o que corresponde a 14,1 milhões de pessoas, segundo a PNAD 2009 (IBGE, 2010).

\section{Análise da situação da criança e do adolescente em relação ao desenvolvimento humano no Brasil}

O PNUD definiu como objetivo para estabelecer o desenvolvimento humano, mudar o enfoque de considerar apenas uma dimensão humana, a econômica social, para o enfoque 
das múltiplas dimensões do homem. Infelizmente, dentro dos parâmetros considerados, os dados aqui colocados apontam para o alto contingente de crianças e jovens que se encontram à margem da trajetória de um país, como o Brasil, que avança tecnológica e industrialmente e cujo PIB/per capita, que em 1993 era de US\$3.008.00 passou para US $\$ 5.860 .00$, ficando em $50^{\circ}$ lugar em 2007, tenha mortalidade infantil e indice de analfabetismo (65․ lugar) maiores que os de outros paises, cujo PNB per capita é menos que a metade do brasileiro e a renda per capita é menor que a sua. Especificamente, a seguir são analisados aspectos fundamentais referentes à saúde e à educação no Brasil.

A pirâmide etária do Brasil (Gráfico 1) apresenta um alargamento das classes de idade mais avançadas, o que significa um aumento da longevidade, portanto, um avanço em relação à saúde da população, ainda que precário, e um estreitamento na base, explicável pelo maior controle de natalidade.

Gráfico 1 - Distribuição da população por sexo, segundo os grupos de idade.

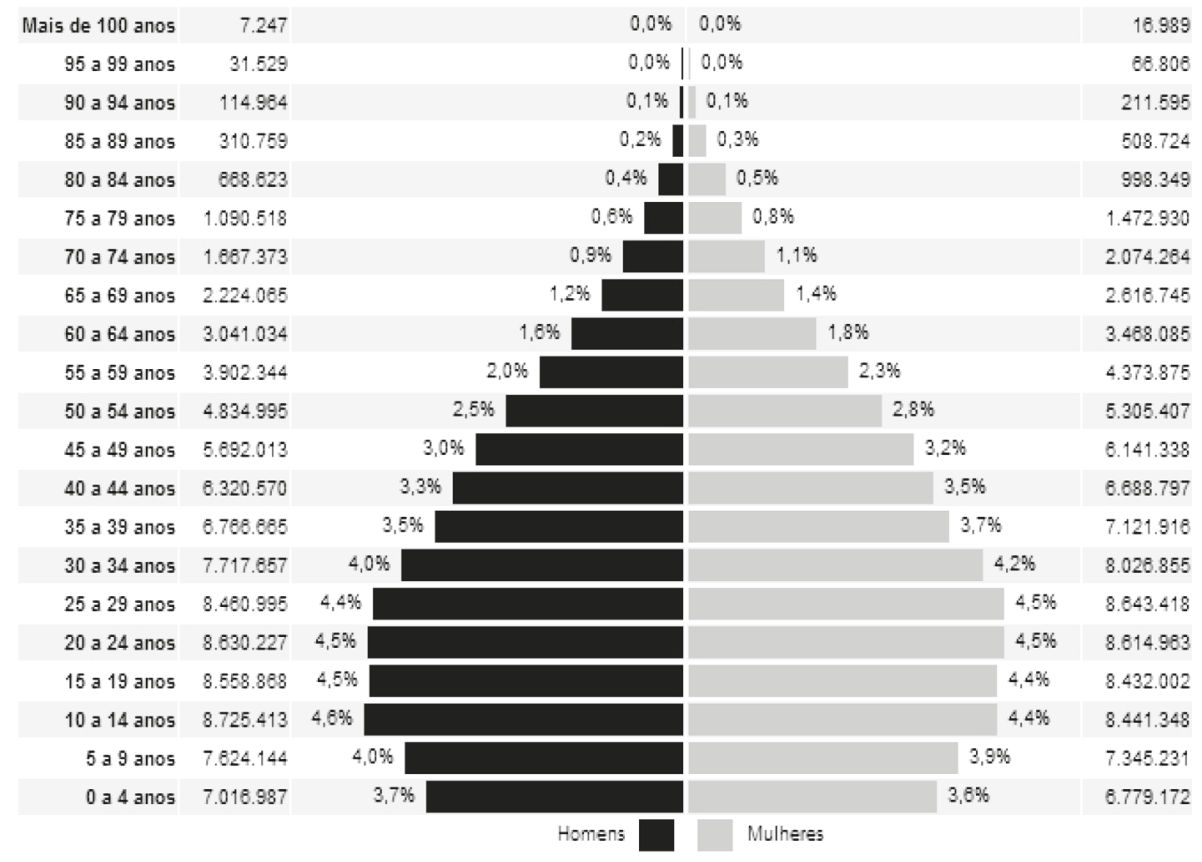

Fonte : IBGE (2011).

São inúmeras as contradições que evidenciam as enormes desigualdades sociais que urgentemente precisam ser eliminadas; o índice de Gini variou de 0,584, em 1981, para 0,589 em 2002 e 0,521 em 2008, persistindo a grave situação da desigualdade social. 


\section{Algumas reflexões sobre a mortalidade infantil e juvenil}

0 desenvolvimento infantil no Brasil melhorou segundo o Índice de Desenvolvimento Infantil (IDI), conforme Relatório de Desenvolvimento Infantil-Sobrevivência Infantil: Unidos pelas Crianças (UNICEF, 2007). Entretanto, as causas mais citadas da situação ainda crítica dos índices de mortalidade infantil são a miséria, a condição socioeconômica da família, a falta de Educação Básica, sobretudo da mãe ou responsáveis pelas crianças a respeito da saúde, aliados à precariedade da rede assistencial médica e social.

Com relação ao adolescente, estudo realizado pelo Instituto de Medicina Social da Universidade do Estado do Rio de Janeiro (UERJ), em 1995, já mostrava o quadro da violência e suas causas, principalmente o homicídio no Rio de Janeiro, até então atribuído à pobreza, à urbanização crescente e desordenada e à fraqueza institucional. Hoje, o mais grave é que tais fatores estão ligados ao tráfico de drogas. No referido estudo é afirmado:

[...] foi principalmente o tráfico de drogas e de armas, que penetrou com incrivel facilidade no segundo principal centro urbano do pais, o maior responsável pelo sofrimento de todos os seus moradores, ricos, remediados pobres. Um erro de diagnóstico repetiu os dogmas de teorias sociológicas vulgares da pobreza e da urbanização acelerada, aliado à incompreensão dos mecanismos institucionais e sociais do crime organizado que atravessa classes e não sobrevive sem o apoio institucional das agências estatais incumbidas de combatê-lo, iniciaram a catástrofe sanitária na mais internacional metrópole brasileira (ZALUAR; NORONHA; FEIJO, 1995, p. 62).

[...] A corrupção policial encontrou no mesmo dogma a razão para não ser combatida: o problema era unicamente "social". Assim, o reducionismo serviu como álibi para não se punir os responsáveis pelas atividades ilegais e discriminatórias contra aqueles que o Estado deveria defender e tratar em centros de saúde e educar preventivamente nas escolas: os jovens, especialmente os mais pobres, que continuam sendo extorquidos e criminalizados pelo uso de drogas e que, por isso, acabam nas mãos dos traficantes e dos assaltantes (ZALUAR; NORONHA; FEIJO, 1995, p. 64).

Entre os jovens, a mortalidade por violências é muito alta, sobretudo nas grandes metrópoles. A taxa padronizada de mortalidade por causas externas cresceu de 1980 a 2003, quase quintuplicando entre homens de 15 a 29 anos de idade (BRASIL, 2009). Do total de homicídios, $92 \%$ ocorreram na população do sexo masculino, sobretudo na faixa $20-29$ anos de idade (40\% do total), seguidos da faixa 30 a 39 anos $(22 \%)$ e de 15 a 19 anos (16\%). Observe-se que a maior incidência está na população de 
escolarização de menos de quatro anos de estudo. A partir de 2000, no entanto, notase uma estagnação e, depois, queda no índice de mortalidade por homicídios entre jovens (Gráfico 2), apesar de ainda se situar nesta faixa o índice mais alto.

Gráfico 2 - Participação de homicídios juvenis (15 a 24 anos) no total de homicídios no Brasil, anos 1979 a 2008.

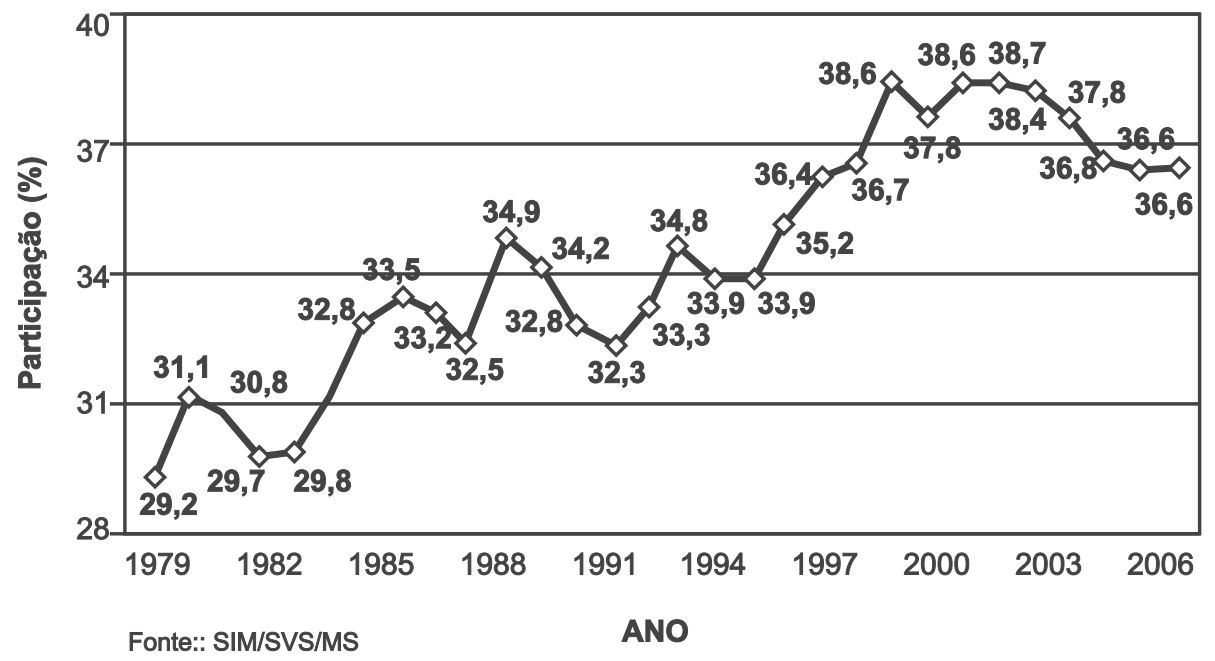

Fonte: Brasil (2008, 2009).

Como permanece a situação da violência até hoje, vale citar Zaluar, que, em 1981, dizia que há como uma linha divisória entre o mundo dos bandidos (ou, como também é chamado, mundo do crime) e o mundo dos trabalhadores. Como o grande problema das famílias era a atração dos jovens pelo que Ihes ofereciam os traficantes locais, parecia que o rito de passagem da criança para a adolescência era a adesão a um dos dois mundos existentes, segundo sua percepção. Há, porém, segundo a autora um tipo de "acordo" na relação das personagens dos dois mundos:

[...] os trabalhadores criam ideias próprias acerca dessas novas personagens: os bandidos, e tentam entender o que se passa hoje no seu bairro e em toda a cidade do Rio de Janeiro. Juntos constroem sua história, marcando mudanças, assinalando passagens, criando personalidades importantes. Juntos criam regras na convivência com os bandidos a fim de escapar do caos resultante desta guerra que, bandidos e trabalhadores (ZALUAR, 1985, p. 133).

A Tabela 1 apresenta um extrato das principais causas da mortalidade na faixa de 10 a 29 anos, em que chamam a atenção os altos índices de causas externas, 
entre elas a morte de jovens por armas de fogo, problema que poderia ser trabalhado através da educação na escola em colaboração com as famílias.

Tabela 1 - Mortalidade no Brasil por ocorrências por faixa etária segundo alguns grupos de causas de taxas mais altas na faixa de 0 a 19 anos-CID-BR-10.

\begin{tabular}{|c|c|c|c|c|c|}
\hline \multicolumn{6}{|c|}{ Frequência referente a óbitos na faixa de 0 a 19 anos extraídos do CID-10 } \\
\hline Tipo de doença & $\begin{array}{l}\text { Menor } \\
\text { de } 1 \text { ano } \\
\end{array}$ & 1 a 4 anos & 5 a 9 anos & 10 a 14 anos & 15 a 19 anos \\
\hline Total & 44.100 & 7.616 & 4.664 & 5.783 & 18.881 \\
\hline $\begin{array}{l}\text { Doenças aparelho } \\
\text { respiratório }\end{array}$ & 2.410 & 1.174 & 356 & 331 & 493 \\
\hline $\begin{array}{l}\text { Doenças infecciosas } \\
\text { e parasitárias } \\
\end{array}$ & 2.354 & 1.025 & 428 & 344 & 496 \\
\hline $\begin{array}{l}\text { Diarréia e Infecciosas } \\
\text { intestinais }\end{array}$ & 1.118 & 355 & 69 & 31 & 25 \\
\hline Gastroenterite & 991 & 307 & 64 & 28 & 18 \\
\hline Doenças bacterianas & 981 & 379 & 140 & 145 & 171 \\
\hline Septicemia & 814 & 246 & 91 & 98 & 105 \\
\hline $\begin{array}{l}\text { Doenças endócrinas, } \\
\text { nutricionais e metabólicas }\end{array}$ & 547 & 302 & 126 & 100 & 158 \\
\hline Causas externas & 1.018 & 1.609 & 1.563 & 2.470 & 13.881 \\
\hline
\end{tabular}

Fonte: Brasil (2009).

\section{Algumas reflexões sobre a realidade educacional}

No que se refere à educação, os dados não são menos assustadores: 6, 8\% da população de sete a 14 anos e 1,9\% de 15 a 24 anos não sabem ler nem escrever (IBGE, 2011)! A taxa de analfabetismo funcional fundamental é muito alta, sobretudo na primeira e segunda séries da zona rural e na rede pública. Em relação ao fluxo, os quadros que se seguem apontam para a alta retenção nas séries. Entre as causas desta situação, são mais frequentemente citadas como responsáveis a condição socioeconômica e a falta de Educação Básica da família, fatores intimamente ligados à causalidade mortalidade infantil, como já vimos.

Analisemos alguns dados importantes para a constatação da gravidade da questão educacional. A taxa de escolarização líquida indica a proporção da população em determinada faixa etária, que se encontra frequentando escola no nível adequado à sua idade (IBGE, 2011). A Tabela 2 deixa clara a alta defasagem de nossos jovens em relação à idade e série que deveriam estar frequentando. 
Tabela 2 - Taxa de escolarização líquida dos adolescentes de 15 a 17 anos de idade, segundo as grandes regiões-1.

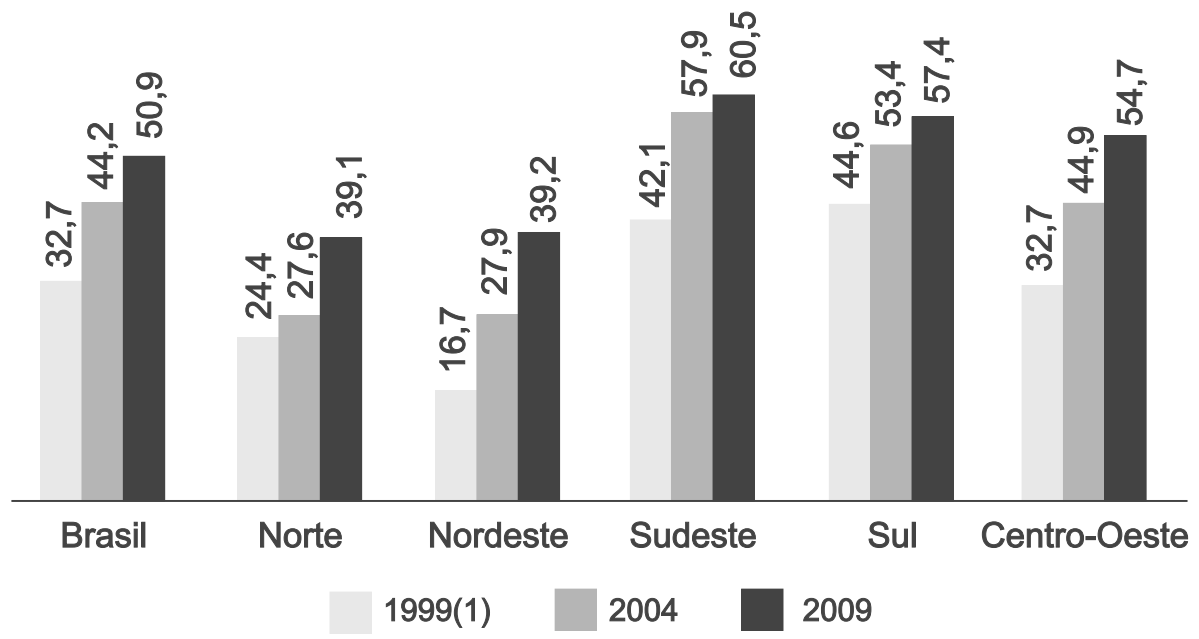

Fonte: IBGE (2010).

0 Quadro 2 também aponta a baixa escolarização das crianças de 10 a 14 anos, cujas taxas traduzem os atrasos e pouco avanço no Ensino Fundamental

Quadro 2 - Média de anos de estudo das crianças de 10 a 14 anos de idade, segundo idade: Brasil 1999/2009.

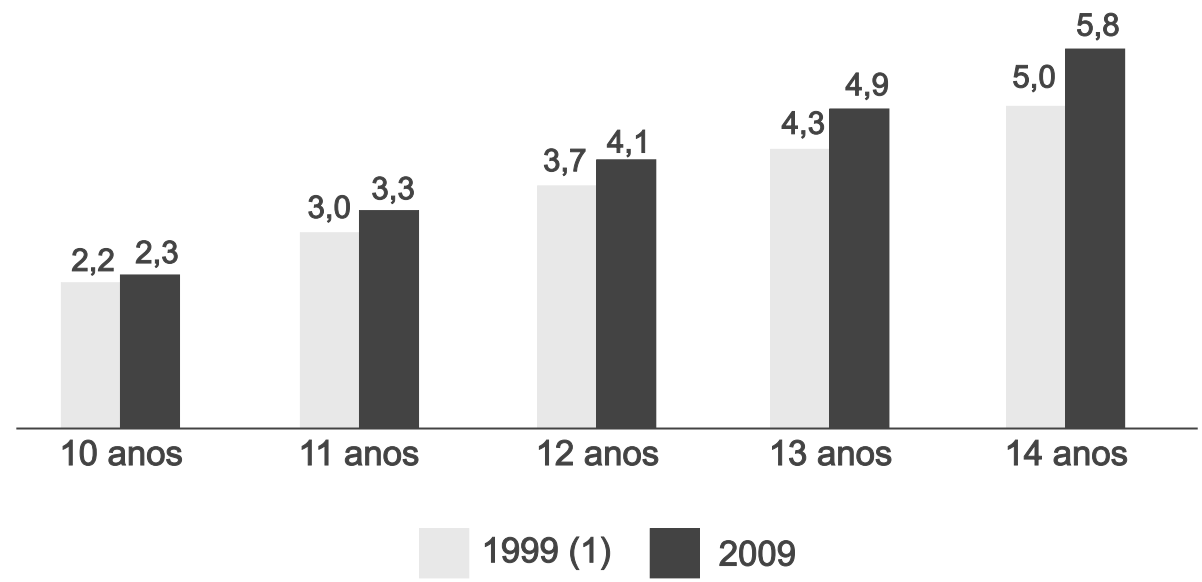

Fonte: IBGE (2010). 
Como dizia o grande filósofo da educação, Trigueiro Mendes (1969, p. 65):

[...] o Brasil de ontem e de hoje é um país que ainda não fez da competência o seu cotidiano; e como a coletividade social vive no cotidiano, ainda não fez da competência o quinhão do povo [...] toda máquina, cada vez mais sofisticada, da vida cotidiana, é transferida pelo povo à responsabilidade exclusiva do pequeno grupo que a maneja.

Sem educação, é impossível o desenvolvimento sustentável, entendido como processo transformador dos modos de existência e ação nos indivíduos, nas instituições e nos grupos, como diz o mesmo autor, pois "os líderes educacionais precisam compreender que toda ação eficaz [...] é, antes de tudo, uma ação que muda a consciência, a própria e a dos outros" (MENDES, 1965, p. 67).

\section{A realidade da criança e do jovem em relação à educação e trabalho}

Segundo a PNAD 2009 (IBGE, 2010), há 2,0 milhões de crianças e jovens de cinco a 15 anos ocupadas no mercado de trabalho, sendo 44\% deste total no Nordeste e $24 \%$ no Sudeste.

Chama a atenção haver 122.679 crianças de cinco a nove anos em situação de trabalho infantil (IBGE, 2011, p.156), a maioria no Nordeste.

Tabela 2 - Crianças, adolescentes e jovens de 10 a 24 anos de idade ocupados, por grupos de idade.

\begin{tabular}{l|r|r|r|r|r|r}
\hline \multirow{2}{*}{$\begin{array}{r}\text { Grandes } \\
\text { regiões }\end{array}$} & \multicolumn{3}{|c|}{ Total (1.000 pessoas) } & \multicolumn{3}{c}{ Taxa de ocupação } \\
\cline { 1 - 7 } Faixa etária & $\begin{array}{r}10 \text { a } 15 \\
\text { anos }\end{array}$ & $\begin{array}{r}16 \text { e } 17 \\
\text { anos }\end{array}$ & $\begin{array}{r}18 \text { a } 24 \\
\text { anos }\end{array}$ & $\begin{array}{r}10 \text { a } 15 \\
\text { anos }\end{array}$ & $\begin{array}{r}16 \text { e } 17 \\
\text { anos }\end{array}$ & $\begin{array}{r}18 \text { a 24 } \\
\text { anos }\end{array}$ \\
\hline Brasil & 1938 & 2190 & 14358 & 9,2 & 32,0 & 62,3 \\
\hline Norte & 215 & 178 & 1125 & 10,7 & 28,6 & 55,3 \\
\hline Nordeste & 844 & 688 & 3914 & 12,9 & 31,8 & 56,7 \\
\hline Sudeste & 463 & 753 & 5972 & 5,8 & 29,6 & 64,4 \\
\hline Sul & 270 & 399 & 2247 & 9,4 & 40,5 & 72 \\
\hline Centro-Oeste & 145 & 172 & 1099 & 9,6 & 33,1 & 64,7 \\
\hline
\end{tabular}

Fonte: IBGE (2010).

Embora ainda não tenha alcançado o nível desejável, tem havido um aumento considerável na proporção de pessoas de 18 a 24 anos, economicamente ativas, com 11 anos de estudo ou mais. Cresceu de 21,7\% (1 999) para 40, 7 (2009) a taxa 
das pessoas nessa faixa etária com 11 anos de estudo e de 7, 9\% para 15, 2\% na mesma faixa com mais de 11 anos de estudo (IBGE, 2010).

Não serão aqui abordadas as questões relativas ao trabalho infantil por se tratar de tema muito especial que exigiria um artigo à parte, consideradas as condições de trabalho na maioria das vezes desumanas. Entretanto, serão feitas sugestões possiveis de serem aplicadas em escalas e modos diferentes, porém exequíveis se adequadas às realidades locais.

Que medidas poderiam ser tomadas a fim de transformar essa realidade de exclusão social diante das constatações aqui referidas? Como sugestão de resposta são apresentadas propostas sobre possiveis ações a serem desenvolvidas no campo da educação.

\section{Polos de educação e inclusão social}

Entende-se que educação, trabalho, saúde, esportes, lazer, cultura e assistência social devam ser os principais vetores a serem acionados para a grande mudança, em direção à conquista da verdadeira cidadania.

\section{a) Algumas definições conceituais}

Educar é libertar. É preciso que a população excluida se conscientize de suas condições de subexistência e tenha uma concepção do mundo que se coadune com seus ideais de libertação para que possa alcançar a cidadania, isto é, direito à participação efetiva no Estado, à proteção deste Estado, bem como perceba que tem deveres para com este Estado. É preciso que perceba os políticos que elege como seus verdadeiros representantes, que tenha o direito de falar e ser ouvida nas Assembléias Legislativas, nas Câmaras de Vereadores, nos Tribunais de Justiça, que tenha seus direitos civis respeitados: direito de ir e vir, pensar, de liberdade religiosa, escolha profissional, segurança, que tenha seus direitos sociais atendidos: saúde, educação, trabalho, lazer, vestuário, alimentação e outros mais, via movimento progressivo de aprofundamento da teoria, orientando-se também pela bioética, entendida como "a moralidade da conduta humana no campo das ciências da vida [...] um sistema de ética capaz de prover diretrizes para uma atuação responsável do ser humano em relação ao futuro" (VARGAS, 2009, p. 17-18) para a construção de uma nova ordem social através de democracia verdadeira.

Para iniciar o processo educacional, é fundamental despertar o desejo de aprender; a escola deve ser atraente. Ao alfabetizar, é preciso levar em conta que a alfabetização é mais do que aprender a ler: é ter acesso à cultura letrada, tendo como suporte a conscientização do papel do homem na vida social e no país, pois é através dela que se registram e difundem dados e são fornecidos elementos para analisar o mundo. Não se pode considerar a criança, o jovem ou o adulto de modo abstrato e genérico, mas propiciar a produção de conhecimentos úteis para sua vida, admitindo as diferenças individuais. 
Como diz Paulo Freire (1974), na alfabetização, é preciso uma base dialógica educador-aluno, conscientizadora de eternos aprendizes, que deverão tornar-se leitores do mundo e produtores de texto para a evolução deste mundo, num processo permanente de libertação, entendida não como anarquia ou autoritarismo, mas processo em que os líderes e o povo aprendem a verdadeira autoridade daquele que orienta e, juntos, buscam transformar a realidade.

Entendendo o trabalho como o processo pelo qual o homem transforma a Natureza para atender às necessidades de satisfação pessoal e aos interesses da sociedade, é preciso considerar que a educação para o trabalho deve ter caráter geral e politécnico, e garantir mobilidade profissional ulterior, assim como incentivar a educação permanente, sobretudo por conta da grande aceleração da ciência e da tecnologia, que abrem inúmeras possibilidades, a cada ano, a cada dia, até mesmo a cada segundo.

Erich Fromm (DEL CAMPO; MARSAL; GARMENDIA, 1976, p. 1.077) dizia que

[...] no processo de moldar a Natureza exterior a ele, o homem se modela a si mesmo [...]. 0 homem se levantou sobre o reino animal pelo próprio feito de sua capacidade criadora [...] definiuse como animal que produz, mas o trabalho não é apenas uma necessidade inevitável, o trabalho é também seu libertador em relação à Natureza, seu criador como ser social e independente.

É preciso distinguir preparação para o trabalho do trabalho infantil propriamente dito. Em pesquisa sobre o Trabalho Infantil, com um grupo de 1.419 crianças que estudavam em escolas públicas nas capitais Belém, Recife, Belo Horizonte, Goiânia, Porto Alegre e São Paulo, concluiu-se que, infelizmente, trabalho para elas, "em vez de instrumento de satisfação, de libertação, se transformou numa forma de reprodução e aprofundamento das desigualdades sociais [...], mas o fundamental é partir do principio de que o trabalho de crianças não é solução para qualquer problema. 0 trabalho infantil é, em si, um problema" (BRASIL, 1997).

É preciso conceber o trabalho não como oposição à liberdade, mas como um campo em que se possa atuar e desenvolver de maneira prazerosa; o trabalho é um valor não só social, mas também individual. A qualificação do trabalhador, hoje, mudou. A personalidade e as qualidades da pessoa são cada vez mais valorizadas, em detrimento da especialização. Os conhecimentos mais gerais, a capacidade de decidir, de expressar-se com clareza e precisão, de adaptação a situações novas, de empreendedorismo, de relacionar-se com os outros, a iniciativa, a honestidade, a perseverança, entre outras qualidades mais, são mais importantes que os conhecimentos específicos, que estão em permanente mudança.

\section{b) Criação de polos de educação e inclusão social}

Por que não basear como lócus da execução de uma nova filosofia os estabelecimentos já existentes, ou seja, as escolas, os estabelecimentos de saúde e postos de 
assistência social? Poder-se-iam definir polos, numa distribuição inicial em Estados, destes em municípios, e destes em estabelecimentos, cujo número seria definido segundo as necessidades locais, numa ação integrada de politicos e profissionais da educação, da saúde, representantes de outros segmentos (transportes, meio ambiente, trabalho, segurança, associações de bairros, instituições sociais e outros) e representantes da sociedade (pais ou responsáveis pelos alunos). Seria um processo realmente democrático, de participação de todos, como o fizeram governos anteriores, tanto no Rio de Janeiro como em outros Estados.

São exemplos, em nível nacional, o "Comunidade Solidária", que tinha como meta usar um novo modo de enfrentar a pobreza e a exclusão social, buscando a participação de todos, e cujo objetivo era mobilizar esforços disponíveis no governo e na sociedade para melhorar a qualidade de vida dos segmentos mais pobres da população, mobilizando as três esferas de governo, sob a orientação de uma secretaria especial, chamada Secretaria Executiva, bem como um Conselho Consultivo, integrando o Terceiro Setor. Foram definidas áreas temáticas e cada Estado constituía sua equipe. Tal equipe era vinculada à Casa Civil da Presidência da República (BRASIL, 1997).

Outra experiência de grande importância nos anos 1967-1989 foi o Projeto Rondon, que mobilizou jovens estudantes de faculdades/universidades de todo o país na promoção do desenvolvimento educacional, social e médico-sanitário em comunidades carentes e tenta restabelecer seu lugar ao ser reiniciado em 2005.

Há, também, o grande exemplo do Projeto da Pastoral da Criança, criado em 1982, em reunião da ONU, a pedido do diretor executivo do UNICEF, James Grunt, ao cardeal D. Paulo Evaristo Arns, e foi responsável por grande redução da mortalidade infantil no Brasil. Foi projetado, criado e desenvolvido por sua irmã, a médica sanitarista Zilda Arns, que o coordenou desde o início até 2010, quando faleceu. A Pastoral do Menor atende, atualmente, a 40.853 comunidades em 4.016 municipios; acompanha 95.000 gestantes, mais de 1,5 milhões de crianças pobres de menos de 6 anos de idade, 1,4 milhões de famílias pobres com mais de 260 mil voluntários, tendo como lema "fé e esperança como forma de solidariedade e conhecimentos sobre saúde, nutrição, educação e cidadania nas comunidades mais pobres para que todos tenham vida e vida em abundância" (UM TRABALHO..., 2010).

Outro Programa de grande eficácia foi o Ano Internacional da Alfabetização, com o apoio do Governo Federal em 1990-1991, em que, só no Estado do Rio de Janeiro, através de polos multiplicadores, agilizando alunos e professores universitários, pessoal da Secretaria de Estado de Educação, sob a liderança da Secretária Fátima Cunha Ferreira Pinto, desenvolveu o Projeto Ler pra Valer, tendo alfabetizado mais de 100 000 pessoas. 0 grande encerramento do Programa se deu em Belém do Pará, quando professores e agentes de todo pais apresentaram seus excelentes resultados. 
A Secretaria de Estado de Educação, naquela época, havia dividido o Estado em regiões em que havia uma escola-piloto, que passava a integrar o rol dos Centros Regionais de Cultura e Educação (CRECEs) e cujo papel era o de escola polo, tendo escolas a ele vinculadas dentro de raio de ação que possibilitasse maior eficácia do atendimento. As ações ali desenvolvidas tiveram participação especial no Programa Nacional de Alfabetização, que culminou com a participação no Programa Internacional de Alfabetização, integrando as atividades, e colocando-as em prática, como na folha da poesia de Thiago de Mello (MELLO apud FREIRE, 1974, p. 28), dedicada a Paulo Freire:

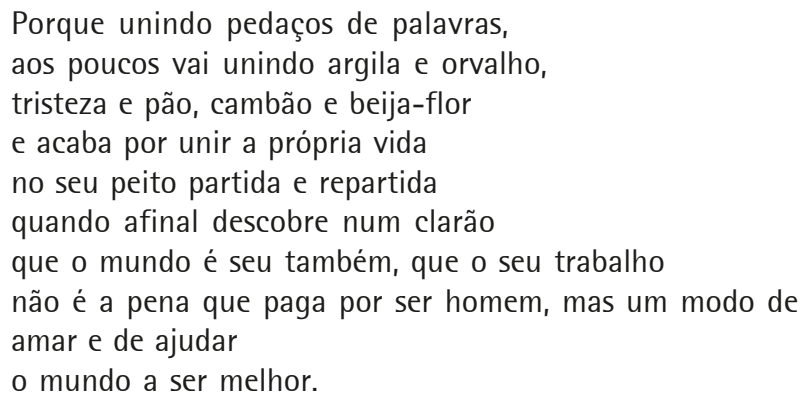

Outro exemplo de integração é o da política da Secretaria Municipal de Saúde, na gestão de Sérgio Arouca, tendo como coordenadora Lucia Souto, em 2001, que buscou realizar uma articulação intersetorial de políticas públicas, resultado de iniciativas comunitárias, envolvendo postos de saúde, escolas, centros de assistência social, Polícia Militar, enfim, iniciativas governamentais e não governamentais, que culminou com o evento "Bangu 40", bairro em que a atuação atingiu estágio mais avançado de verdadeira integração comunitária.

Como o foco na área da educação, apresenta-se aqui uma sugestão para o caso de o polo estar localizado em escolas, entendendo a educação na escola como o rito de passagem que permite a inserção do sujeito numa sociedade mais ampla, visando a incentivar sua participação no sentido de transformá-la para melhor atender aos interesses nacionais.

A escola, per se, deve propiciar ao aluno condições que lhe possibilitem a construção de projeto existencial, fruto de reflexão crítica e consciente, pautada por valores morais, bioéticos e religiosos, para que ele tenha compreensão do mundo que se coadune com o objetivo social comum de crescimento, libertação das condições de subsistência e construção de um mundo melhor.

Os currículos, aí incluídos os conteúdos a serem estudados, não podem ser estáticos: devem constituir o conjunto de experiências vivenciadas pelo indivíduo, de modo que este venha a conhecer melhor a realidade, refletir sobre ela e capacitarse a construir e reconstruir a ciência, a exercer a ação transformadora no desenvol- 
vimento científico, artístico, cultural e espiritual e também na abertura de espaço democrático, antecipador da justiça social. Deverão ativar as estruturas lógico-matemáticas, linguísticas, espaçotemporais e socioafetivas dos alunos, a fim de que estes melhor questionem, compreendam e atuem e, assim, tenham melhores condições para uma ação construtiva, com coerência entre o pensar e o agir, ultrapassando o conformismo, a submissão e a irracionalidade.

A escola não pode permanecer distante da dinâmica social: os conhecimentos a transmitir não podem se restringir a aqueles contidos em livros didáticos; precisam ir além e penetrar nas demais relações da sociedade maior, através de outros recursos, incluindo os da mídia escrita, falada, televisada, eletrônica, se não quiser cristalizar-se.

Está na hora de confiar, valorizar, ouvir os educadores, professores, profissionais da educação e dar-Ihes também condições físicas e financeiras para assumir seu papel, seu compromisso profissional, sobretudo aqueles das escolas públicas, recriando, na escola, o espaço que alunos, pais, responsáveis, percebam como seu, porque é público e, portanto, de todos.

Dificilmente, a escola terá sucesso em atingir seus objetivos se não se preocupar em conhecer as aspirações, interesses e valores internos do grupo em que atua, bem como conhecer o sentido que a educação tem para esse grupo a fim de traçar suas linhas de ação; só assim será percebida como escola do povo. Caso contrário, ela corre o risco de ser força estranha e ver esvaziada a execução de projetos por mais maravilhosos que sejam. Enquanto instituição de fora, a escola não terá significado para a comunidade, estará dentro dela, sem pertencer a ela. Sua eficácia só se tornará real no momento em que, rompendo as barreiras socioculturais, conseguir ai se integrar, oferecendo igualdade de condições de acesso e de oportunidade para todos. E só esta eficácia conduzirá à valorização do magistério, à valorização da escola pública e poderá funcionar como uma das forças transformadoras da realidade, ao satisfazer as necessidades do povo, a produzir conhecimento e bem social, comprometida com os valores coletivos.

A educação para o trabalho deve estar intimamente ligada à própria natureza das atividades desenvolvidas na escola, incentivando as atitudes de responsabilidade, senso crítico, aceitação do outro, cooperação, zelo profissional, além do próprio conhecimento teórico, da busca da criatividade, da construção da ciência e do domínio do uso atualizado e adequado da tecnologia.

0 professor reconhecerá seu papel de mediador, numa relação dialogal, descobridor das capacidades de seus alunos, e não o dominador que "dá aula", "ensina coisas", como se os alunos fossem meros receptáculos do saber das classes dominantes. Para isto, é preciso lembrar que, além das horas em sala de aula, o professor 
precisa despender tempo suficiente para preparar suas aulas, avaliar os trabalhos realizados pelos alunos, corrigir provas, além de horário para frequentar cursos de aperfeiçoamento, seminários, congressos e outros. As escolas precisam, também, de pessoal para que não haja descontinuidade no processo ensino-aprendizagem, seja por falta justificada, ou para assistência especial aos alunos que dela necessitam para recuperação paralela ou outro tipo de assistência, seja cognitiva, psicológica ou social, através da orientação educacional e pedagógica.

Não se pode inculpar a democratização do ensino pela queda dos padrões; fazse mister trabalhar, lutar mesmo, para que se deixe de responsabilizar as crianças pelo fracasso escolar, e reconhecer que é o tipo de educação e o modo de educar que não estão adequados à realidade e às necessidades. É preciso assumir uma nova postura no tratamento do bem público, respeitando a dignidade da pessoa humana e o patrimônio cultural do Estado, tornando a escola pública instituição de vanguarda na realização dos ideais democráticos de dignidade, igualdade e fraternidade. Como sugestão de modo de execução do que aqui está proposto, postularia o estabelecimento de polos, conforme descrito nos próximos parágrafos.

Entende-se a democratização como processo sociopolítico que se caracteriza pela igualdade de todos os membros de um grupo ou comunidade social e política para participar com lealdade e honestidade das funções políticas e gozar objetivamente e com justiça dos serviços públicos. Só assim, serão superados tensões e conflitos políticos e sociais, mediante a participação autônoma e solidária, promovendo a justiça social. Para isto, é mister aprimorar a educação de base, não aquela que ensina algo ao ouvinte (o aluno), mas aquela que o politiza, buscando, com ele, os meios de transformar o meio em que vive.

O Brasil possui 194.929 escolas de Ensino Básico, nos Estados e municípios do país, além de postos de saúde, de assistência social, de assistência médica. É possível mapeá-los e estabelecer polos de educação, saúde e assistência social, em que também seriam inseridos importantes centros de assistência e promoção social já existentes e que desenvolvem ações de suma importância para a população. Estes constituiriam espaços integradores, difusores e realimentadores de ações e integração comunitária, onde se efetivariam o repensar da educação, da assistência médica e social, da saúde comunitária, do espaço cultural, do social e da segurança, de modo integrado, com base na realidade sociocultural local.

Diante dos propósitos da educação na escola, da quantidade e pluralidade de tipos de atendimento, diretos e indiretos, bem como localização geográfica, conhecimento e competência das pessoas envolvidas em suas múltiplas funções, é razoável que se eleja a escola como principal polo de transformação para atingir as metas que se pretende alcançar. 
Tais polos estariam articulados, seriam monitorados e avaliados permanentemente com a participação integrada dos órgãos competentes afins. Seriam espaços verdadeiramente democráticos que, num processo civilizatório, muito contribuiriam para uma sociedade mais digna, mais justa, mais igual

Para a execução desta proposta, sugere-se o desenvolvimento das quatro fases a seguir:

\section{Fase 1: Planejamento}

a) 0 primeiro passo seria o planejamento das ações, começando pela definição dos polos por parte dos órgãos centrais, tais como as secretarias estaduais e municipais, enfatizando a preparação do pessoal envolvido. As escolas polo, por sua vez, teriam seu espaço físico adequado às funções que virão a desempenhar e seu pessoal preparado para a definição e execução destas funções. Teriam que contar com pessoal administrativo, professores e demais profissionais da educação competentes e dispostos a dinamizar os processos de implementação de uma nova filosofia de trabaIho para o desenvolvimento comunitário, num processo civilizatório.

b) 0 segundo passo seria a convocação das escolas polo para formulação de políticas para a execução dos programas a serem definidos numa ação conjunta, incluindo órgãos governamentais responsáveis e escolas polo para definirem as escolas e órgãos de assistência médica e social a que estariam diretamente vinculados.

\section{Fase 2: Algumas sugestões de ações importantes}

a) chamada escolar, através da qual seria realizado o primeiro contato com as crianças/adolescentes e suas familias ou responsáveis. Desta instância poderiam participar, além das próprias escolas, em seus diferentes graus e modalidades de ensino, Serviços de Assistência Social, órgãos ligados à área da Saúde e programas vigentes.

b)controle da presença dos alunos. A ausência, mesmo por um dia, precisaria ser analisada pela escola. Os pais ou responsáveis deveriam ser imediatamente contactados para revelarem a causa. 0 controle da saúde e demais controles sociais seriam feitos por pessoal lotado nas escolas, e, caso houvesse necessidade, seria feito o encaminhamento para a devida assistência, o que propiciaria maior envolvimento das familias dos alunos e dos núcleos de assistência social, que além do controle, providenciariam orientação para as necessidades básicas da população, havendo mais transparência e eficácia nas ações.

c) articulação dos diversos graus e modalidades de ensino, inclusive o Ensino Superior sobretudo de cursos ligados ao magistério. As escolas poderiam se tornar campos de estágio para o ensino superior, como também as Faculdades 
e Universidades proporcionarem cursos de aperfeiçoamento e elaboração de pesquisas e avaliação voltadas para os interesses dos alunos das escolas de nivel fundamental e médio, da comunidade e da sociedade em geral.

\section{Fase 3: Ampliação e articulação de atividades diversificadas.}

As escolas polo deveriam articular procedimentos educativos de maior amplitude, tais como cursos de aperfeiçoamento, promoção de atividades culturais diversas (seminários, palestras, filmes, peças de teatro, eventos culturais (dança, canto, exposições de pintura, literatura, artesanato, culinária,...), eventos esportivos, civicos, através de seus grêmios. Poderiam ser promovidas palestras articuladas com outros setores, como, por exemplo, saúde (individual e pública), atendimento médico-hospitalar e odontológico, utilização de assistência médico-sanitária por parte dos serviços locais e outras mais a serem definidas conforme as necessidades.

Em relação às escolas, é preciso manter a formação permanente, a educação continuada, a articulação ente os vários niveis: Infantil, Fundamental, Médio e Superior, num processo permanente de realimentação e integração, constituindo os polos campo de estudo, análise, aplicação e avaliação, realização de estágios e renovação pedagógica permanentes.

Caberia também às escolas polo descobrir e valorizar a cultura local, através de levantamento das atividades artísticas, folclóricas, artesanais de sua localidade e vizinhas, promover cursos, exposições, festejos, recitais e outras manifestações culturais, assim como em nivel nacional (datas comemorativas, festas), valorizando o espírito patriótico.

Outra atividade dos polos seria a criação de oficinas de preparação para o mundo do trabalho, articulando-se com outros órgãos, buscando convênios com cursos técnicos em entidades tais como SENAI, SENAC, EMATER e outras similares, bem como visitas a instituições e palestras de profissionais.

Deverão ser dinamizadas as Associações de Pais para que estes se integrem de fato ao desenvolvimento comunitário pretendido, em colaboração com órgãos e agências locais, inclusive incentivando a pertença às associações de bairros, e às atividades comunitárias, desenvolvendo o espírito de solidariedade.

\section{Fase 4: Monitoramento e Avaliação}

Enfim, também competiriam às equipes dessas escolas polo, o monitoramento e a avaliação de todo este processo, a fim de obter os indicadores para alcançar a transformação da realidade local de modo participativo, numa relação dialógica Governo e Sociedade. 
Concluindo, esta seria uma experiência de um possivel realizável, consistente, que favoreceria a construção da identidade das pessoas e conquista da cidadania através da valorização da educação como principal vetor da verdadeira promoção do desenvolvimento humano. Entretanto, faz-se mister que os profissionais da educação, assim como os da saúde e assistentes sociais sejam valorizados, não apenas enquanto pessoas capazes de serem agentes desta mudança, mas tenham condições de trabalho e salário compatíveis com os valores de mercado, um plano de cargos e carreiras condizentes com as funções que exercerão e terem condições de vida compativeis com sua competência e esperança de ascensão, sem o que, dificilmente haverá candidatos a ocupar tais postos de trabalho.

\section{Referências}

BRASIL. Constituição (1988). Constituição República Federativa do Brasil. Brasília, DF: Senado Federal, 1988.

BRASIL. Lei no. 8.069, de 13 de julho de 1990. Diário Oficial da União, Brasília, DF, 16 jul. 1990a.

BRASIL. Ministério da Saúde. Secretaria de Vigilância em Saúde. Departamento de Análise da Situação de Saúde. Sistema de Informações sobre Mortalidade (SIM): período 2007. Brasília, DF, 2008. Disponivel em: <http:// www.educabrasil.inep.gov.br/Resultado.jsp>. Acesso em: 11 abr. 2011.

. Ministério do Trabalho e Emprego. Sistema de Informações Sindicais. Brasilia, DF, 1997. Disponivel em: <http://sis.dieese.org.br/1 abr. 97. xml>. Acesso em: 9 abr. 2011.

. O PNUD e seus objetivos. Brasília, DF, 1990b. Disponivel em: <www. Planalto.gov/publi_/com 1.htm>. Acesso em: 11 maio 2011.

Sistema de Informações sobre Mortalidade (SIM): período 2008. Brasilia, DF, 2009. Disponivel em: <http://tabnet.datasus.gov.br/cgr/ tabcgi.exe.sim-CID-BR-10>. Acesso em: 11 maio 2011.

FROMM, E. In: DEL CAMPO, S.; MARSAL, J. F.; GARMENDIA, J. A. Diccionario de Ciencias Sociales. Madrid: Instituto de Estudios políticos, 1976. p. 1077.

IBGE. Pesquisa Nacional por Amostra de Domicílios 2009. Rio de Janeiro, 2010.

IBGE. Sintese de indicadores sociais: uma análise das condições de vida da população brasileira 2010. Rio de Janeiro, 2011. 
FREIRE, P. Educação como prática da Liberdade. Rio de Janeiro: Paz e Terra, 1974.

MENDES, D. T. (Coord.). Filosofia da educação brasileira. Rio de Janeiro:

Civilização Brasileira, 1996.

TITO, R. Criança e paz. Brasília, DF: Ed. do Autor, 1990.

UM TRABALHO que faz a diferença. Pastoral da Criança, Curitiba, 2010. Disponível em: <https://www.pastoraldacrianca.org.br>. Acesso em: 11 maio 2011.

UNICEF. Situação mundial da infância 2008: sobrevivência infantil: unidos pelas crianças. Brasilia, DF, 2007.

UNITED NATIONS DEVELOPMENT PROGRAMME. Human development report 1990. New York: Oxford University Press, 1990.

VARGAS, A. Bioética: impactos da pós-modernidade. Rio de Janeiro: LECEU, 2010.

VASCONCELOS JÚNIOR, H. Curso de direito da infância e da juventude: Lei nº. 8.060, de 90 (Estatuto da Criança e do Adolescente): dos direitos fundamentais. [S. I.], [200?]. Disponivel em: <xa.yimg.com/kq/groups/22957401/.../ AULAS+EM+WORD.doc>. Acesso em: 27 fev. 2011.

ZALUAR, A. A máquina e a revolta: as organizações populares e o significado da pobreza. São Paulo: Brasiliense, 1985.

ZALUAR, A.; NORONHA, J.; FEIJO, C. Pobreza não gera violência. Ciência Hoje, Rio de Janeiro, v. 20, n.115, p. 62-69, 1995.

Recebido em: 13/05/2011

Aceito para publicação em: 03/08/2011 